\title{
Deslocamentos femininos e prostituição
}

\author{
Trânsitos: brasileiras nos \\ mercados transnacionais do \\ sexo.
}

PISCITELLI, Adriana.

Rio de Janeiro: EdUERJ, 2013. 272p.

A visão da prostituição como atividade imoral e que vulnerabiliza as mulheres envolvidas neste mercado ainda é recorrente nos discursos oficiais da sociedade contemporânea. Apesar de não ser considerada crime no Brasil e em outros países ocidentais, a atividade de prostituição ainda está sujeita a regulamentações e manobras políticas, na medida em que a mobilidade e a permeabilidade entre o trabalho sexual e o vínculo afetivo ultrapassam as fronteiras transnacionais e o controle de migrações. Nesse sentido, o debate em torno da prostituição, como meio de vida, está longe de apresentar consenso. Principalmente, enquanto as mulheres envolvidas neste trabalho permanecerem sem voz ativa e estigmatizadas pelo contexto indissolúvel entre exploração sexual e tráfico de pessoas.

Em sua pesquisa etnográfica multisituada, desenvolvida ao longo de sete anos, Adriana Piscitelli nos apresenta uma nova perspectiva para o mercado do sexo, através do relato de mulheres brasileiras que se deslocaram entre o Brasil e o sul da Europa, cheias de aspirações e procurando por diferentes formas de realização pessoal através da prostituição. Acompanhar estas brasileiras no mercado do sexo transnacional permitiu à pesquisadora o estabelecimento de uma associação particular entre diversas culturas e interpretações de temas vinculados ao mercado do sexo, dentro de diferentes cenários de sociabilidade em Fortaleza, na Espanha e na Itália.

Ao longo do livro Trânsitos: brasileiras nos mercados transnacionais do sexo, Adriana Piscitelli revela suas interpretações sobre a prostituição transnacional, entre diferentes tópicos (mercado do sexo, indústria do sexo, tráfico de pessoas, turismo sexual e casamento misto) e agentes sociais (prostitutas, instituições governamentais, grupos feministas, empresários da indústria do sexo e clientes), procurando compreender como algumas ideias sobre o mercado do sexo e as relações conjugais/amorosas são ativadas e ressignificadas entre disjunções de contextos culturais e geográficos diferenciados. Ao mesmo tempo, a autora separa e reagrupa novas associações entre essas temáticas, estabelecendo uma comunicação clara e sem cair em simplificações. De acordo com Piscitelli, "a etnografia mostrou a relevância de tratar do assim chamado 'turismo sexual', a prostituição e o tráfico de pessoas como problemáticas diferenciadas".'

O grande debate sobre o comércio sexual no Brasil e na Europa teve início a partir da década de 1990, com a preocupação em torno da prostituição vinculada ao turismo sexual internacional no nordeste do Brasil e no aumento das brasileiras como profissionais do sexo em países europeus, principalmente na Espanha. Neste panorama, Piscitelli revela que, ao iniciar sua pesquisa, não havia intenção de abordar a problemática do tráfico internacional de pessoas. Mas este contexto se impôs sobre a pesquisa na medida em que se verificou a existência de uma associação automática entre turismo sexual e tráfico de pessoas, tanto no Brasil quanto na Europa. A autora não nega a existência do tráfico de pessoas para fins de exploração sexual. Porém, através da pesquisa, Piscitelli considera que:

$A$ vinculação entre deslocamentos nos mercados do sexo e tráfico de pessoas recria noções que permeiam a literatura internacional e os debates feministas sobre prostituição. Tais noções são atualizadas por instâncias diversificadas organizações dedicadas a proteger os direitos da criança, movimentos de mulheres e organismos que combatem o crime organizado transnacional -, em discussões nas quais confluem interesses que operam em diversos planos. $^{2}$

Compreender a prostituição requer estar atento aos vários discursos que permeiam esta atividade. Sendo uma prática profissional recente no contexto ocidental, a partir da segunda metade do século XIX, surge uma divisão social formada por uma nova classe de mulheres públicas, categorizadas como prostitutas e segregadas em espaços sociais, delimitando as práticas do sexo comercial de suas vidas privadas. Já a cidade pós-industrial ocidental vem marcada por mudanças na maneira como o sexo é comercializado enquanto atividade recreativa e confinado aos ambientes fechados. O serviço sexual, mediado por novos meios de comunicação (celulares e internet), vincula a emoção ao contexto comercial e pouco distingue os "domínios eróticos 
públicos e privados". ${ }^{3}$ Estes diferentes modelos de prostituição permanecem misturados no contexto atual, principalmente quando o intercâmbio de sexo por dinheiro acontece no Brasil ou envolvendo pessoas brasileiras no mercado exterior.

O grau de integração e independência das entrevistadas, no contexto migratório, demonstra atuações autônomas e trânsitos sazonais destas mulheres entre suas cidades brasileiras de origem e os centros urbanos europeus. A autora apresenta revelações das entrevistadas que não estavam livres de preocupação quanto à exploração econômica ou dos riscos da deportação, quando em situação irregular. Ao longo da pesquisa, porém, não surgiram relatos confirmando a exploração sexual e o confinamento dessas mulheres pelo crime de grupos organizados para o tráfico internacional de pessoas.

Em geral, o levantamento de campo fol realizado entre 2004 e 2011 , "com o fim de compreender as dinâmicas e as noções envolvidas nos deslocamentos de brasileiras nos mercados transnacionais do sexo". ${ }^{4} \mathrm{~A}$ autora participou de espaços de discussão, seminários e realizou entrevistas com instâncias governamentais e não governamentais, entre grupos de prostitutas $e$ de feministas, procurando compreender as formulações de políticas públicas sobre o mercado do sexo e o tráfico de pessoas, tanto no Brasil quanto na Europa.

A etnografia teve início em Fortaleza, na pesquisa de campo pelos circuitos do turismo sexual desta cidade. O levantamento envolveu a observação intensiva e entrevistas de profundidade, com duração de 18 meses, em diferentes momentos entre 2000 e 2008. No total, foram realizadas 95 entrevistas com turistas estrangeiros e com os nativos, vinculados ao turismo e à prostituição, havendo maior proximidade com 12 das mulheres entrevistadas, que faziam trânsitos sazonais entre o Norte da ltália e a cidade de Fortaleza. Algumas das mulheres entrevistadas estavam vinculadas ao turismo sexual, enquanto outras migraram dentro de outros contextos. $O$ trabalho de campo também esteve vinculado ao contato com organizações não governamentais, consulado brasileiro e universidade, ambos na cidade de Milão. E no embalo desses deslocamentos pela Europa, a autora também realizou pesquisa de campo na Espanha, durante 12 meses, entre 2004 e 2011 . Neste período, visitou diferentes regiões espanholas, entre Barcelona, Madri, Granada, Bilbao, Antequera e realizou pequenas incursões na Galícia. Além das 19 entrevistas em profundidade com brasileiras envolvidas no mercado do sexo espanhol, o trabalho de campo envolveu a observação junto a entidades que apoiam as prostitutas no contexto de oferta de serviços, nas ruas das cidades investigadas, em clubes e apartamentos. Para a aproximação com empresários da indústria do sexo e com algumas trabalhadoras houve o intermédio de ONGs, que dão assistência aos migrantes vinculados à prostituição. Nestas organizações também foram feitas 28 entrevistas com profundidade.

Levando em conta as experiências dessas brasileiras e situando-as no âmbito das discussões sobre migração internacional e tráfico de pessoas, o eixo articulador das diversas fases da etnografia foi a análise das relações entre noções e práticas sociais, procurando compreender as dimensões de agência presentes nessas articulações. ${ }^{5}$

Na parte intermediária do livro, Piscitelli contextualiza seus deslocamentos etnográficos e situa sua pesquisa em diferentes escalas. Apresenta, também, um panorama geográfico dos países, das cidades e na compreensão das categorias espaciais urbanas onde a indústria do sexo define diferentes valores para a exploração econômica e na qualidade ambiental de adaptação das prostitutas, que surgem de diferentes países emergentes da América Latina, da África e da Europa Oriental.

De acordo com a pesquisa, existe uma imensa variedade de serviços sexuais envolvendo bordéis, boates, bares, casas de massagem, linhas telefônicas, sexo virtual, motéis, cinemas, revistas e vídeos pornôs, serviços de acompanhantes e, até mesmo, agências matrimoniais. Diante desta diversidade, o termo prostituição obscurece a compreensão dos serviços sexuais existentes para atender a um jogo de oferta e demanda muito mais amplo. Mas, nem sempre existe um grau completo na mercantilização do sexo, envolvendo a troca de dinheiro por serviços sexuais. Há diferença no nível de prostituição, principalmente no caso brasileiro. Conforme a autora, em suas inserções de campo na cidade de Fortaleza, alguns benefícios são obtidos pela troca de favores sexuais, envolvem mobilidade social e melhorias na condição de vida. E, normalmente, a retribuição por presentes, passagens de avião e outros bens materiais, como, no caso, entre jovens mulheres e homens mais velhos e ricos, são associações conjugais relacionadas ao comércio sexual. Estas relações de reciprocidade também são recriadas nos cenários do turismo sexual, no intercâmbio envolvendo a mercantilização parcial do sexo por benefícios econô- 
micos, de maneira autônoma, entre pessoas locais mais pobres e viajantes de países ricos. Apesar de o sexo servir como moeda de troca, estas relações "não são pensadas como prostituição pelas pessoas envolvidas". ${ }^{6}$

Dentro dos estudos de gênero, Piscitelli questiona as abordagens feministas sobre a prostituição. Genericamente, existem duas visões antagônicas do feminismo vinculadas à relação das mulheres com o sexo. Por um lado, a prostituição é vista como um uso abusivo do sexo e a prostituta seria um objeto sexual, vítima da violência desta transação comercial. Do outro lado, o sexo é visto como fonte de poder enquanto a prostituta detém sua autonomia sexual, que desestabiliza o controle patriarcal sobre suas sexualidades. Nesta segunda visão, mais próxima da opinião da autora a partir dos relatos etnográficos, a prostituição é uma forma de resistência e subversão, como parte do contexto da ordem sexual existente. Piscitell ainda relata que a discriminação de gênero, atualmente, se aplica também aos transexuais, transgêneros e intersexes, e não apenas às mulheres. Neste caso em especial, a leitura sobre os mercados do sexo deve considera essas diferenças para a compreensão particular dos intercâmbios sexuais e da prostituição.

A noção do trabalho sexual, vista como uma categoria ocupacional reconhecida, surgiu a partir do ano de 1970, nos Estados Unidos. A ideia da prostituição como trabalho defende que as trabalhadoras do sexo possuem as mesmas condições que exigem conter as emoções no desempenho de suas atividades, similar ao trabalho das fisioterapeutas, enfermeiras e aeromoças. Contudo, a busca por atividades no sexo comercial continua percebida como meio de alcançar melhor qualidade de vida, no plano material e simbólico, principalmente entre trabalhadoras do sexo em condições de pobreza, racismo, preconceito e desigualdades de gênero. Essas relações do mercado transnacional do sexo revelam maior circulação de pessoas entre as fronteiras nacionais, articulando diferentes agentes situados nos dois lados deste mercado global. Este movimento de transgressão e resistência das prostitutas revela autonomia entre os diferentes estilos de deslocamento, permitindo uma nova leitura dos fluxos transnacionais, sem a necessária relação com o crime organizado. Dos cenários desbravados e interpretados pela pesquisadora, acompanhando a trajetória de brasileiras pobres envolvidas comercial e emocionalmente com homens de países ricos, surgem revelações que desmistificam a proble- mática do turismo sexual e do tráfico internacional de pessoas para fins de exploração sexual das mulheres envolvidas na prostituição.

Participando como feminista e atenta ao relato das pessoas diretamente envolvidas no mercado do sexo transnacional, Piscitelli desconstrói o discurso recorrente da mídia e de organizações mundiais na maneira como delimitam o problema e fazem associações entre temas de complexidades distintas, como tráfico internacional de pessoas, a vulnerabilidade das mulheres envolvidas e o comércio de exploração sexual. A adequação de leis nacionais e os tratados supranacionais não têm (apenas) o efeito de proteger as pessoas supostamente envolvidas no tráfico de pessoas. Defender o direito das mulheres originárias de lugares pobres e vitimizar sua condição na exploração sexual torna-se uma justificativa para camuflar o esforço institucional destes países europeus em evitar o fluxo migratório de mulheres estrangeiras no mercado crescente da prostituição (facilitando a deportação das brasileiras irregulares) e desestimular a migração regularizada para este continente. Inclusive, através dos casamentos mistos, envolvendo pessoas de diferentes nacionalidades.

Fazendo uma leitura crítica sobre o Protocolo de Palermo, a autora associa diretamente seus artigos e aplicações, em proteção aos direitos das vítimas envolvidas na prostituição transnacional, com as preocupações dos governos na luta contra o tráfico de pessoas, no combate ao crime organizado, à migração e à prostituição. Em apoio a estas medidas, que atrapalham o princípio de autonomia da vontade e a mobilidade das prostitutas, está a abordagem feminista neoabolicionista. A visão destas feministas considera a prostituta vítima da exploração sexual e a indústria do sexo como crime imoral, que envolve a prostituição e o tráfico de pessoas. Enquanto, em outro polo das correntes feministas, que consideram o sexo como fonte de poder para as mulheres, "o sexo é visto como uma tática cultural que pode reforçar o poder, mas também pode desestabilizá-lo".? Esta segunda corrente do pensamento feminista enxerga as prostitutas com autonomia, utilizando ativamente o sexo como resistência à dominação masculina.

Ao longo da sua pesquisa, Adriana Piscitelli reconhece mudanças no seu posicionamento como feminista, inicialmente contrário à prostituição. Suas ideias foram se modificando ao longo da pesquisa e diante da diversidade de relações nos intercâmbios sexuais envolvendo um conjunto heterogêneo de mulheres, que não eram vítimas miseráveis do mercado do sexo e da prostituição. 
Quando inseridas nos circuitos do turismo sexual de Fortaleza, não demonstravam estar sujeitas à vulnerabilidade e abusos que caracterizam o tráfico de pessoas. Nem mesmo quando migravam nos mercados do sexo em direção a países do sul da Europa. "A exploração da qual [estas mulheres] são objeto no mercado transnacional do sexo é puramente comercial e jamais sexual, contribuindo para olhar de maneira crítica as bases teóricas nas quais se apoia a noção de exploração sexual nas perspectivas feministas". ${ }^{8}$

Mesmo sujeitas aos efeitos da racialização ligada à região e à nacionalidade de sua origem, estas mulheres morenas e brasileiras demonstraram capacidade de negociar seus espaços de agência, ${ }^{9}$ quando inseridas em categorias de corpos e no desempenho sexual atribuídos pelo mercado do sexo e pelas relações matrimoniais na valorização da sensualidade, do cuidado com a saúde do corpo e no ato de carinho. O grau de interação social entre as entrevistadas era variado. A maioria mantinha o contato com suas famílias de origem, principalmente através de ligações telefônicas, contribuindo com o envio de dinheiro e nas decisões cotidianas de suas famílias no Brasil. As que deixaram o mercado do sexo, ao casar no contexto migratório, eram mais propensas ao isolamento social, restrito ao contexto familiar. Para Piscitelli, o processo de negociação da intimidade e da moralidade não está livre de tensões.

A relativa imprecisão de fronteiras entre os mercados do sexo e do casamento, que se expressa na escolha de cônjuges no âmbito do sexo transnacional e da prostituição, parece sugerir modificações no traçado de limites morais. Entretanto, as narrativas das entrevistadas sobre relações conjugais, amorosas e familiares mostram o constante esforço necessário para delinear as qualidades morais apropriadas para esse tipo de intimidade, que se expressa na reconfiguração de categorias de diferenciação. ${ }^{10}$

Os deslocamentos femininos analisados na modalidade de migração e vinculados ao mercado do sexo transnacional revelam a busca por condições de vida melhores do que as encontradas no Brasil, mesmo que não haja a garantia de sucesso no exterior. Essas trajetórias estão marcadas por redes de apoio informais e, até mesmo, por dívidas. Ainda assim, este movimento migratório não pode estar associado diretamente a grupos criminosos na organização destes fluxos transnacionais. De acordo com o relato etnográfico de Adriana Piscitelli, podemos considerar a inserção dessas mulheres nos mercados do sexo e mediante o casamento com estrangeiros como estratégias de ascensão social dentro das dinâmicas de deslocamentos mundiais, desafiando as fronteiras políticas, econômicas e remodelando as representações contemporâneas do gênero feminino.

\section{Notas}

12013 , p. 55.

22013 , p. 20.

${ }^{3}$ Piscitelli, 2013, p. 29

${ }^{4}$ Piscitelli, 2013, p. 21.

5 Piscitelli, 2013, p. 21

${ }^{6}$ Piscitelli, 2013, p. 27

${ }^{7}$ Piscitelli, 2013 , p. 38.

${ }^{8}$ Piscitelli, 2013, p. 55.

9 Para a autora, a noção de agência representa a "capacidade de ação, mediada social e culturalmente" (p. 22), indo além da compreensão de agência como sinônimo de resistência e não se restringindo a esta acepção.

${ }^{10}$ Piscitelli, 2013, p. 227

Marcos Sardá Vieira

Universidade Federal da Fronteira Sul - UFFS Universidade Federal de Santa Catarina - UFSC 